\title{
Lightning induced voltages on multiconductor power distribution line
}

\author{
P.D. Kannu and M.J. Thomas
}

\begin{abstract}
The magnitude and waveshape of the induced voltages on $33 \mathrm{kV}$, three-phase overhead power distribution lines of both single-circuit and double-circuit configurations due to a nearby lightning stroke have been computed. The effect of ground conductivity and the presence of multiple conductors on the magnitude and waveshape of the induced voltages are also studied. A comparison is made on the induced voltages for a single-conductor overhead line as well as for single- and double-circuit power distribution line configurations. It has been observed that the ground impedance as well as the presence of multiple conductors has a significant influence on the induced voltages. The first peak of the induced voltage at the line termination is found to be less when only ground conductivity is taken into account in the horizontal electric field computation. It is reduced further when ground conductivity is included in the calculation of both the horizontal electric field as well as in the coupling of field to overhead conductor. At the midpoint of the line, the influence of ground conductivity on the induced voltage is such that it increases the first peak. The first peak of induced voltage near the line termination gets reduced in the presence of other conductors in a multiconductor line, whereas it remains almost constant at the midpoint of the line. However, the second peak increases with number of conductors in both cases. It is also observed that the induced voltage on a conductor is reduced if the number of conductors in a power distribution line circuit are increased. In the time-domain coupling equation used for the computation of induced voltage, the ground impedance is usually represented by a convolution integral. The low-frequency approximation used for the transient ground resistance presents singularity as $t \rightarrow 0$. However, for the solution of the convolution integral a new approximate expression has been used, which circumvents the singularity.
\end{abstract}

\section{Introduction}

Overvoltages induced by indirect lightning can cause frequent outages in power systems as well as damage to power distribution system components, e.g. distribution transformers [1]. Indirect lightning may cause more microinterruptions than direct strikes because of their more frequent occurrence [2]. Several theoretical studies have been done for the computation of induced voltage on overhead lines due to a nearby lightning return stroke. The method of computation of induced voltage consists of

1 Modelling the lightning return stroke channel.

2 Calculation of electromagnetic field generated by the lightning return stroke.

3 Modelling of electromagnetic field coupling to overhead line and thereby computation of induced voltage.

In the literature, different approximations have been used for the calculation of induced voltages [3-8]. They are:

1 The ground is assumed as a perfect conductor and hence the distortion introduced by the finite ground conductivity on the electromagnetic field radiated by lightning is neglected [3-5].

2 Ground conductivity is included in the calculation of horizontal electric field using the wave-tilt formula, which is not valid for short distances of $200 \mathrm{~m}$. It is valid for radiation fields and grazing incidences only [7].

3 The horizontal electric field is calculated using the Cooray-Rubinstein approximation [8], which is equal to the sum of the horizontal electric field calculated at line height over perfectly conducting ground and the horizontal electric field calculated at ground level over the finitely conducting ground.

4 The effect of the ground and line impedance on the propagation of the induced voltage along the line is neglected or the ground impedance is taken as a constant resistance in the coupling equation [6].

5 The ground impedance, which depends on frequency, is represented in the time-domain coupling equation by a convolution integral in which low-frequency approximation of transient ground resistance is used $[9,10]$.

Even though there are many publications on lightning induced overvoltages on overhead lines, none of them has considered the influence of the number of conductors and ground resistivity on the induced voltages in multiconductor lines representing an actual three-phase power distribution line. This paper studies the effect of ground conductivity as well as the presence of multiple conductors on the magnitude and waveshape of the induced voltage on 
overhead power distribution lines. In the paper lightning induced voltages are computed for $33 \mathrm{kV}$ three-phase singlecircuit and double-circuit distribution lines for the following cases: (i) assuming ground as a perfect conductor, (ii) including the ground conductivity only in the calculation of horizontal electric field, and (iii) including the ground conductivity in the calculation of horizontal electric field as well as in the field coupling to overhead conductors. The influence of the presence of other conductors on the induced voltage in a multiconductor system is also studied.

\section{Modelling return stroke channel}

To calculate the lightning electromagnetic field, a straight vertical channel over a perfectly conducting ground is assumed. Figure 1 shows the geometry for the calculation of induced voltage due to a lightning return stroke on a nearby overhead line. The electric and magnetic fields generated by the lightning return stroke can be obtained if the spatialtemporal distribution of the lightning return stroke current $i\left(z^{\prime}, t\right)$ and its velocity along the channel are known. There are several return stroke models that have been proposed by earlier researchers that specify these parameters [11]. In the present study the modified transmission line (MTL) model has been adopted. According to this model, the lightning current is allowed to decrease with height while propagating upward along the channel and is described as follows:

$$
i\left(z^{\prime}, t\right)=e^{\left(-z^{\prime} / \lambda\right)} i\left(0, t-z^{\prime} / v\right)
$$

where $v$ is the velocity of the return stroke and $\lambda$ is the decay constant that accounts for the effect of the vertical distribution of charge stored in the corona sheath of the leader and subsequent discharge during the return stroke phase.

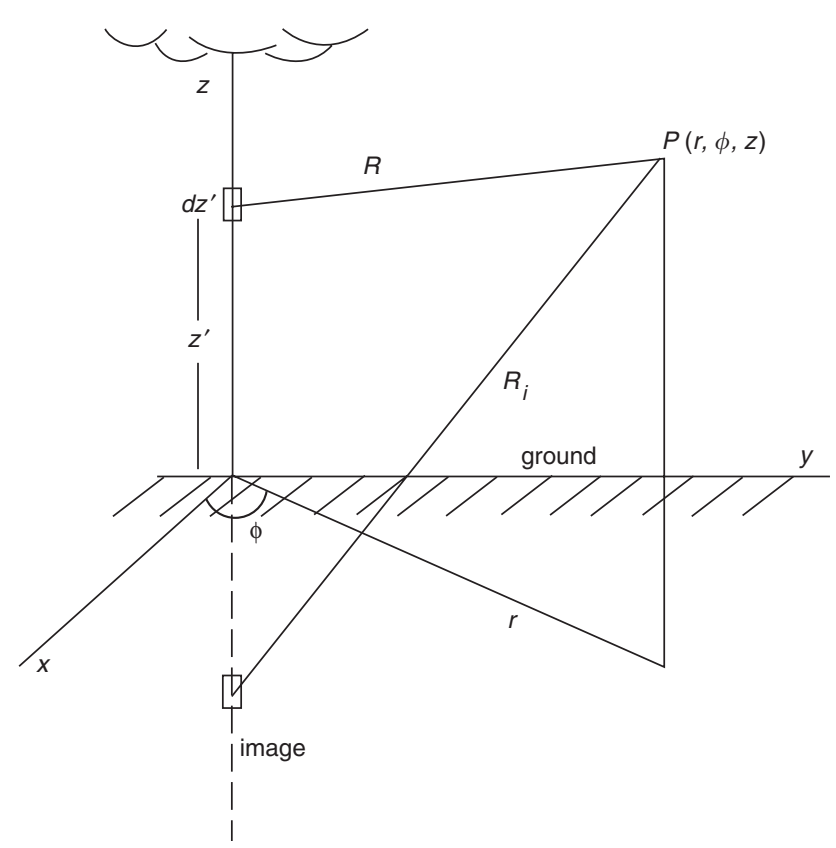

Fig. 1 Sketch showing lightning channel and its image used in calculating return stroke fields

\section{Computation of electromagnetic fields generated by return stroke}

For the computation of the induced voltage, when ground is assumed as a perfect conductor, the horizontal and vertical components of the electric field due to the return stroke are required. But for the calculation of the induced voltage, including the finite ground conductivity, the magnetic field is required when using the CoorayRubinstein formula. For a current element of length $d z^{\prime}$ at a height $z^{\prime}$ and carrying a current $i\left(z^{\prime}, t\right)$, the vertical electric field $d E_{z}(r, z, t)$, the horizontal electric field $d E_{r}(r, z, t)$ and the magnetic field $d H_{\phi}(r, z, t)$ at a point $P(r, \phi, z)$ over a perfectly conducting ground in cylindrical co-ordinates in the time domain are given by the following expressions [7, 12]:

$$
\begin{aligned}
d E_{z}(r, z, t)= & \frac{d z^{\prime}}{4 \pi \epsilon_{0}}\left[\frac{2\left(z-z^{\prime}\right)^{2}-r^{2}}{R^{5}} e^{\left(-z^{\prime} / \lambda\right)}\right. \\
& \int_{0}^{t} i\left(0, \tau-z^{\prime} / v-R / c\right) d \tau \\
& +\frac{2\left(z-z^{\prime}\right)^{2}-r^{2}}{c R^{4}} e^{\left(-z^{\prime} / \lambda\right)} i\left(0, t-z^{\prime} / v-R / c\right) \\
& \left.-\frac{r^{2}}{c^{2} R^{3}} e^{\left(-z^{\prime} / \lambda\right)} \frac{\partial}{\partial t} i\left(0, t-z^{\prime} / v-R / c\right)\right]
\end{aligned}
$$

$$
\begin{aligned}
d E_{r}(r, z, t)= & \frac{d z^{\prime}}{4 \pi \epsilon_{0}}\left[\frac{3 r\left(z-z^{\prime}\right)}{R^{5}} e^{\left(-z^{\prime} / \lambda\right)}\right. \\
& \int_{0}^{t} i\left(0, \tau-z^{\prime} / v-R / c\right) d \tau \\
& +\frac{3 r\left(z-z^{\prime}\right)}{c R^{4}} e^{\left(-z^{\prime} / \lambda\right)} i\left(0, t-z^{\prime} / v-R / c\right) \\
& \left.+\frac{r\left(z-z^{\prime}\right)}{c^{2} R^{3}} e^{\left(-z^{\prime} / \lambda\right)} \frac{\partial}{\partial t} i\left(0, t-z^{\prime} / v-R / c\right)\right]
\end{aligned}
$$

$$
\begin{array}{r}
d H_{\phi}(r, z, t)=\frac{d z^{\prime}}{4 \pi}\left[\frac{r}{c R^{2}} e^{\left(-z^{\prime} / \lambda\right)} \frac{\partial}{\partial t} i\left(0, t-z^{\prime} / v-R / c\right)\right. \\
\left.+\frac{r}{R^{3}} e^{\left(-z^{\prime} / \lambda\right)} i\left(0, t-z^{\prime} / v-R / c\right)\right]
\end{array}
$$

where $\epsilon_{0}$ is the permittivity of free space and $c$ is the velocity of light. $R=\sqrt{r^{2}+\left(z-z^{\prime}\right)^{2}}$ is the distance from the current element to the observation point. The above equations use the MTL lightning return stroke model discussed in the previous Section. The total vertical and horizontal electric field and magnetic field are obtained by integrating along the lightning return stroke channel and its image. The horizontal component of the electric field with the finite conductivity of the ground is calculated using the Cooray-Rubinstein formula [13]. The horizontal electric field $E_{r g}(z=h, r)$ as per the above formula is given by

$$
\begin{aligned}
E_{r g}(z=h, r)= & E_{r}(z=h, r) \\
& -H_{\phi}(z=0, r) \frac{\sqrt{\mu_{0}}}{\sqrt{\epsilon+\sigma_{g} / j \omega}}
\end{aligned}
$$

where $E_{r}(z=h, r)$ is the Fourier-transform of the horizontal electric field at height $h, H_{\phi}(z=0, r)$ is the Fourier-transform of the azimuthal component of the magnetic field at ground level, $\mu_{0}$ is the permeability of air, and $\epsilon$ and $\sigma_{g}$ are the permittivity and conductivity of the ground, respectively. Both $E_{r}(z=h, r)$ and $H_{\phi}(z=0, r)$ are calculated assuming a perfect conducting ground using (3) and (4).

\section{Modelling of coupling of electromagnetic field to overhead line}

In this work, the coupling model as proposed by Agrawal et al. [14] has been used. The presence of finite ground 
conductivity is included in the coupling equation by two terms, namely (i) series per-unit length impedance, which accounts for earth return, and (ii) transverse ground admittance. Both these terms are frequency dependent [15]. The transverse ground admittance is generally neglected for overhead power distribution lines. The frequency-dependent series ground impedance is represented in the time-domain coupling equation by a convolution integral [9]. Hence the coupling equations, including the ground impedance in the time domain, gets modified as follows:

$$
\begin{gathered}
\frac{\partial}{\partial x}\left[v_{i}^{s}(x, t)\right]+\left[L_{i j}\right] \frac{\partial}{\partial t}\left[i_{i}(x, t)\right]+\int_{0}^{t}\left[\xi_{i j}(t-\tau)\right] \\
\times \frac{\partial}{\partial \tau}\left[i_{i}(x, \tau)\right] d \tau=\left[E_{x}^{i}\left(x, h_{i}, t\right)\right] \\
\frac{\partial}{\partial x}\left[i_{i}(x, t)\right]+\left[G_{i j}\right]\left[v_{i}^{s}(x, t)\right]+\left[C_{i j}\right] \frac{\partial}{\partial t}\left[v_{i}^{s}(x, t)\right]=0
\end{gathered}
$$

where $\left[E_{x}^{i}\left(x, h_{i}, t\right)\right]$ is the vector of horizontal component of the incident electric field along the conductor at conductor height $h_{i}$; the sub-index $i$ denotes the particular wire of the multiconductor line; $\left[L_{i j}\right],\left[G_{i j}\right]$ and $\left[C_{i j}\right]$ are the inductance, conductance and capacitance matrices per unit length of the line, respectively; $\left[i_{i}\right]$ is the line current vector; $\left[\xi_{i j}\right]$ is the transient ground resistance matrix and is equal to the inverse Fourier-transform of $\left[Z_{g i j} / j \omega\right]$, i.e. $\xi_{i j}(t)=F^{-1}\left[\frac{Z_{g_{i j}}}{j \omega}\right]$; and $\left[Z_{g_{i j}}\right]$ is the ground impedance matrix. The internal impedance of the line is neglected. $\left[v_{i}^{s}\right]$ is the scattered voltage vector on the $i$ th conductor.

The scattered voltage is related to the total line voltage $v_{i}(x, t)$ by:

$$
\left[v_{i}(x, t)\right]=\left[v_{i}^{s}(x, t)\right]+\left[v_{i}^{i}(x, t)\right]
$$

where $\left[v_{i}^{i}(x, t)\right]$ is called the incident voltage given by

$$
\left[v_{i}^{i}(x, t)\right]=-\int_{0}^{h_{i}} E_{z}^{i}(x, z, t) d z
$$

$E_{z}^{i}(x, z, t)$ is the incident(or inducing) vertical electric field at $x$ at a height of $z$.

The boundary conditions for the scattered voltage vector $\left[v_{i}^{s}(x, t)\right]$ are

$$
\begin{array}{r}
{\left[v_{i}^{s}\left(x_{0}, t\right)\right]=-\left[Z_{1}\right]\left[i_{i}\left(x_{0}, t\right)\right]+\int_{0}^{h_{i}} E_{z}^{i}\left(x_{0}, z, t\right) d z} \\
{\left[v_{i}^{s}\left(x_{0}+l, t\right)\right]=\left[Z_{2}\right]\left[i_{i}\left(x_{0}+l, t\right)\right]} \\
+\int_{0}^{h_{i}} E_{z}^{i}\left(x_{0}+l, z, t\right) d z
\end{array}
$$

where $\left[Z_{1}\right]$ and $\left[Z_{2}\right]$ are the terminating impedence matrices. A single-wire overhead line equivalent circuit using this model is shown in Fig. 2. The coupling equations are solved using the finite-difference time domain (FDTD) method. The conductors are subdivided into successive and equally spaced voltage and current nodes. Two successive nodes of the same type are separated by an interval $\Delta x$. The two end points of the conductors are defined as voltage nodes.

\section{Time-domain approximation for transient ground resistance}

For the case of multiconductor lines, the ground impedance is a full matrix with diagonal (self-impedance) and offdiagonal terms. Accurate approximations for the ground

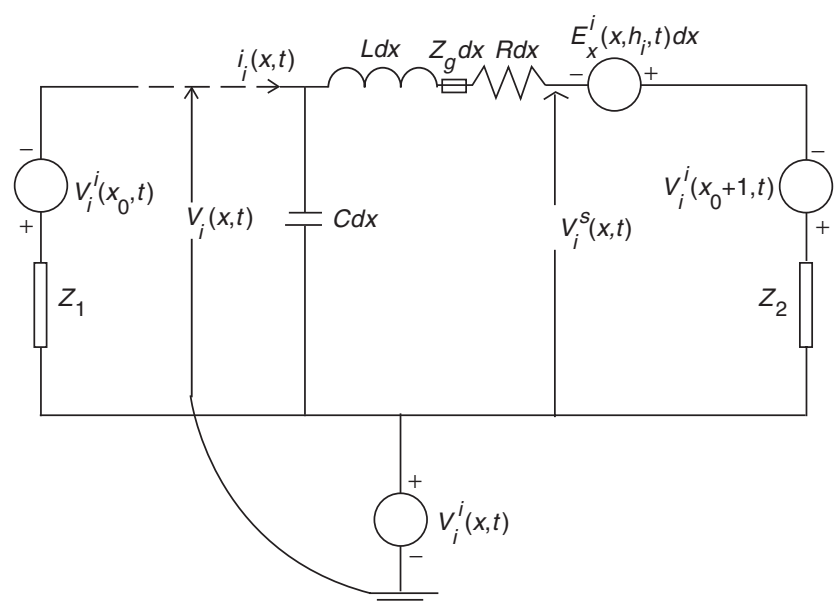

Fig. 2 Equivalent circuit of single-wire overhead line excited by lightning return-stroke field (conductance neglected)

impedance corresponding to single-wire lines have been presented by Sunde and Vance $[16,17]$. The expression for the mutual ground impedance between the conductors in low-frequency approximation, i.e. assuming $\sigma_{g} \gg \omega \epsilon_{0} \epsilon_{r}$, is given by [18]:

$$
Z_{g_{i j}}=\frac{j \omega \mu_{0}}{\pi} \int_{0}^{\infty} \frac{e^{-\left(h_{i}+h_{j}\right) x} \cos \left(r_{i j} x\right)}{\sqrt{x^{2}+j \omega \mu_{0} \sigma_{g}}+x} d x
$$

where $r_{i j}$ is the distance between the two conductors in the horizontal plane.

The general expression for the ground impedance matrix does not have an analytical inverse Fourier transform. However, a low-frequency approximation of the inverse Fourier transform of the ground self impedance is given by [18]:

$$
\xi_{i i}(t)=\frac{\mu_{0}}{4 \pi \tau_{i i}}\left[e^{\frac{\tau_{i i}}{t}}-1-\frac{2}{\sqrt{\pi}} \sum_{n=1}^{\infty} a_{n}\left(\frac{\tau_{i i}}{t}\right)^{\frac{2 n+1}{2}}\right]
$$

where $\tau_{i i}=h_{i}^{2} \mu_{0} \sigma_{g}$ and $a_{n}=\frac{2^{n}}{1,3, \ldots,(2 n+1)}$.

The off-diagonal terms of the transient ground resistance matrix are given by

$$
\begin{aligned}
\xi_{i j}(t)= & \frac{\mu_{0}}{\pi T_{i j}}\left[\frac{1}{2 \sqrt{\pi}} \sqrt{\frac{T_{i j}}{t}} \cos \left(\theta_{i j} / 2\right)\right. \\
& +\frac{1}{4} e^{T_{i j} \cos \left(\theta_{i j}\right) / t} \cos \left(\frac{T_{i j}}{t} \sin \left(\theta_{i j}\right)-\theta_{i j}\right) \\
& \left.-\frac{1}{2 \sqrt{\pi}} \sum_{n=0}^{\infty} a_{n}\left(\frac{T_{i j}}{t}\right)^{\frac{2 n+1}{2}} \cos \left(\frac{2 n-1}{2} \theta_{i j}\right)-\frac{\cos \left(\theta_{i j}\right)}{4}\right]
\end{aligned}
$$

with

$$
\left[\frac{h_{i}+h_{j}}{2}+j \frac{r_{i j}}{2}\right]^{2} \mu_{0} \sigma_{g}=T_{i j} e^{j \theta_{i j}}
$$

The elements of the transient ground resistance matrix $\left[\xi_{i j}(t)\right]$ present singularity as $t \rightarrow 0$. Loyka [19] has shown that the ground transient resistance does not become singular for $t \rightarrow 0$, if it is calculated without the low-frequency approximation and has shown that $\xi_{i j}(t) \rightarrow$ constant for $t \rightarrow 0$. This analytical expression for the transient ground resistance is modified by Rachidi et al. [20] These analytical expressions are non-singular and describe within the limits of transmission-line theory. However, in this paper for the calculation of the induced voltage, the incremental time $\Delta t$ is selected 
such that $\xi_{i j}(t)$ can be calculated using (14) at $t=\Delta t$. In solving the convolution integral the ground transient resistance is taken as constant in the range $t-\Delta t<\tau<t$. For the calculation of line current at the $n$th incremental time $t=n \Delta t$, the expression for the convolution integral [21]
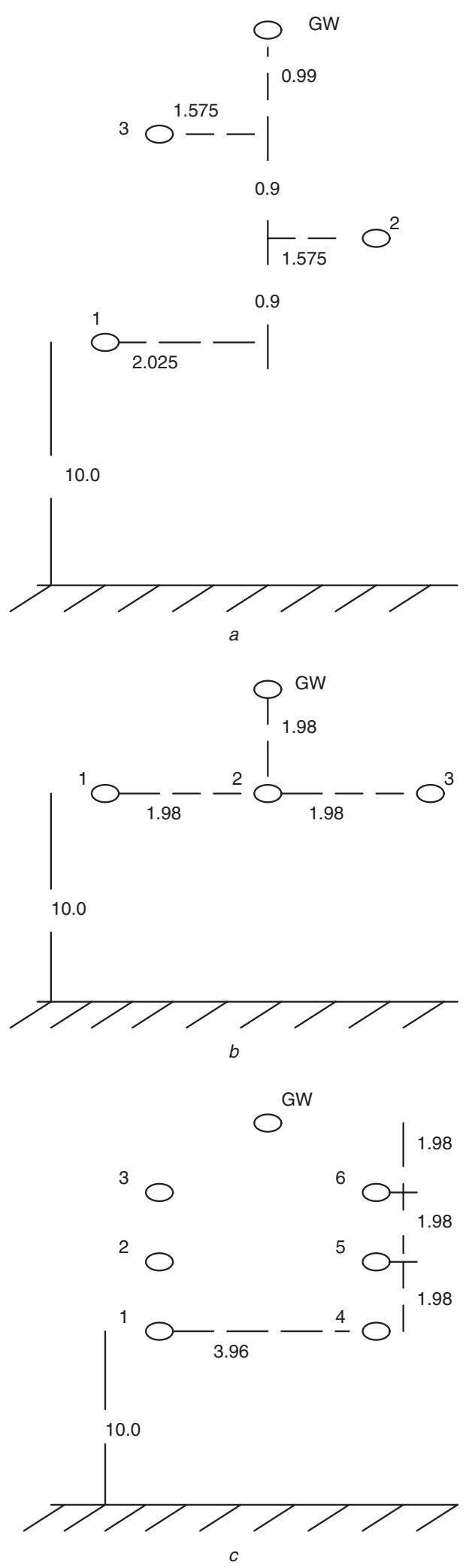

Fig. 3 Conductor configurations used

$a$ Single-circuit vertical

$b$ Single-circuit horizontal

$c$ Double-circuit

GW-ground wire

All dimensions in metres at any node is obtained as follows:

$$
\begin{aligned}
\int_{0}^{n \Delta t} \xi(t-\tau) \frac{\partial i}{\partial \tau} d \tau= & \sum_{m=0}^{m=n-2} \xi^{m+1}(t)\left(i^{n-m}-i^{n-m-1}\right) \\
& +\xi^{1}(t) \frac{\left(i^{n}-i^{n-1}\right)}{2}+\xi^{n}(t) \frac{\left(i^{1}-i^{0}\right)}{2}
\end{aligned}
$$

with $\xi^{k}(t)$ and $i^{k}$ representing the value of the transient ground resistance for the elements in $\left[\xi_{i j}(t)\right]$ and the line current, respectively, at time $t=k \Delta t$.

\section{Results and discussions}

The lightning induced voltages are computed for $33 \mathrm{kV}$ three-phase single-circuit and double-circuit overhead power distribution lines. The configurations of the lines are shown in Fig. 3. For the calculation of induced voltages, a lightning return stroke channel base current of $12 \mathrm{kA}$ peak and $40 \mathrm{kA} / \mu \mathrm{s}$ waveform, which represents a typical subsequent return stroke, is chosen [7]. The return stroke velocity is taken as $1.3 \times 10^{8} \mathrm{~m} / \mathrm{s}$. The length of the transmission line is taken as $1 \mathrm{~km}$. The line conductors are terminated at both ends by the characteristic impedance of the lines and that of the earth wire by the tower surge impedance [22]. The induced voltages are calculated at the line ends as well as at the mid-point of the line for a lightning stroke located at a distance of $50 \mathrm{~m}$ from the line centre and equidistant to the line ends.

To study the effect of the finite conductivity of the ground, the induced voltages are computed for the following three cases:

1 The ground is assumed as a perfect conductor.

2 The ground conductivity is taken into account only in the calculation of horizontal electric field.

3 The effect of ground conductivity is considered in the calculation of both horizontal electric field as well as in the field coupling to the overhead conductors.

The ground conductivity $\sigma_{g}$ and the relative permittivity $\epsilon_{r}$ are taken as $0.001 \mathrm{~S} / \mathrm{m}$ and 10.0 respectively. The induced voltage on different conductors at line termination for the various configurations are shown in Figs. 4-13. The induced

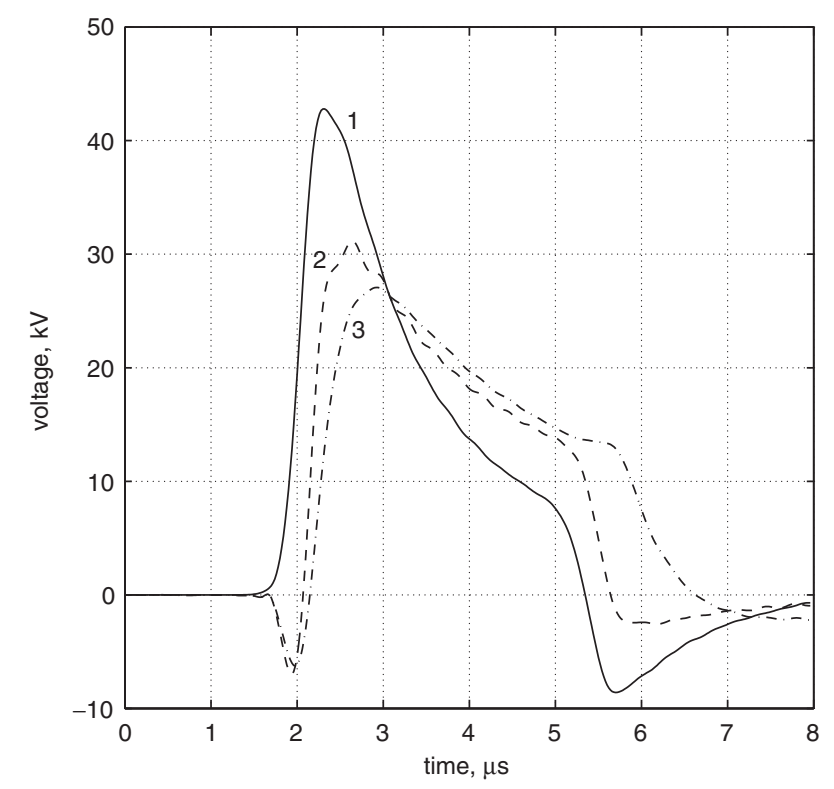

Fig. 4 Induced voltage on conductor 1 of single-circuit vertical configuration at line termination 


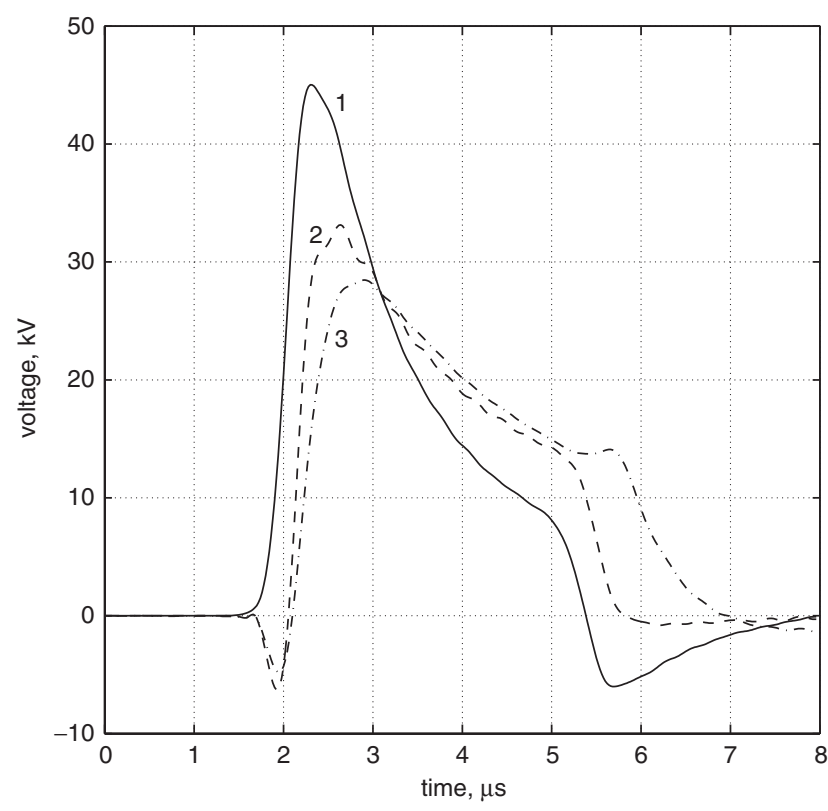

Fig. 5 Induced voltage on conductor 1 of single-circuit horizontal configuration at line termination

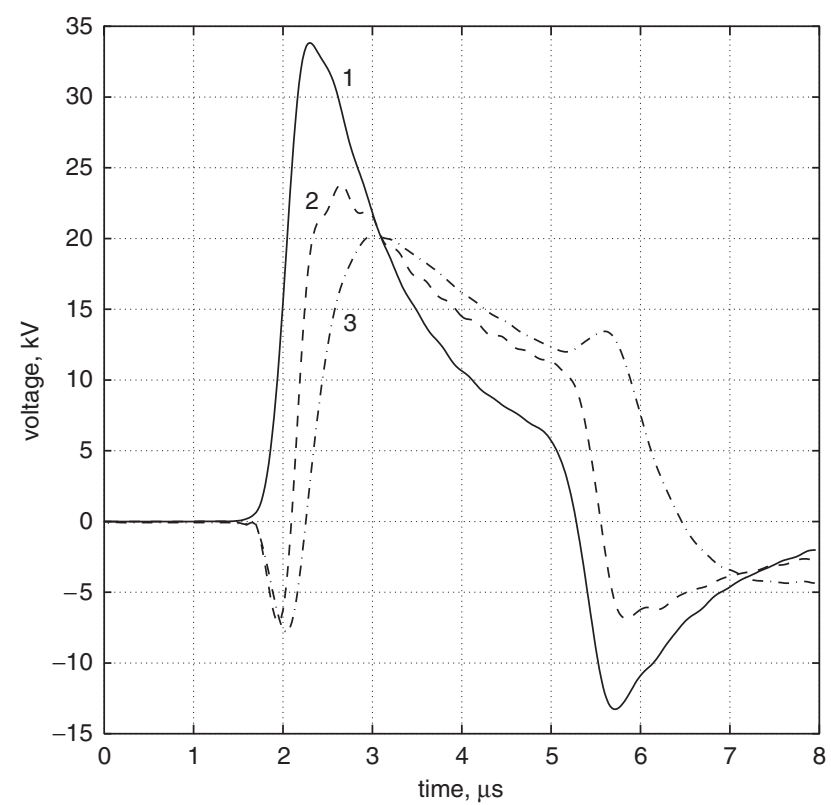

Fig. 6 Induced voltage on conductor 1 of double-circuit configuration at line termination

voltages at the mid-point of the line are shown in Figs. 14-16. In Figs. 4-16, curve 1 represents the induced voltage waveform when ground is assumed as a perfect conductor, curve 2 represents the induced voltage when ground conductivity is considered only in the calculation of horizontal field, and curve 3 represents the induced voltage when ground conductivity is considered in the computation of both the horizontal field as well as in the field coupling to the overhead conductors.

For a lightning return stroke current of $12 \mathrm{kA}$ at ground level, the plots show that the positive peak of the induced voltage at line terminations for conductor 1 is about $43 \mathrm{kV}$ for single-circuit vertical configuration, $46 \mathrm{kV}$ for singlecircuit horizontal configuration and $34 \mathrm{kV}$ for double-circuit configuration if ground is assumed as a perfect conductor. The negative peak of the induced voltages at line terminations is 9,6 and $13 \mathrm{kV}$, respectively. From the

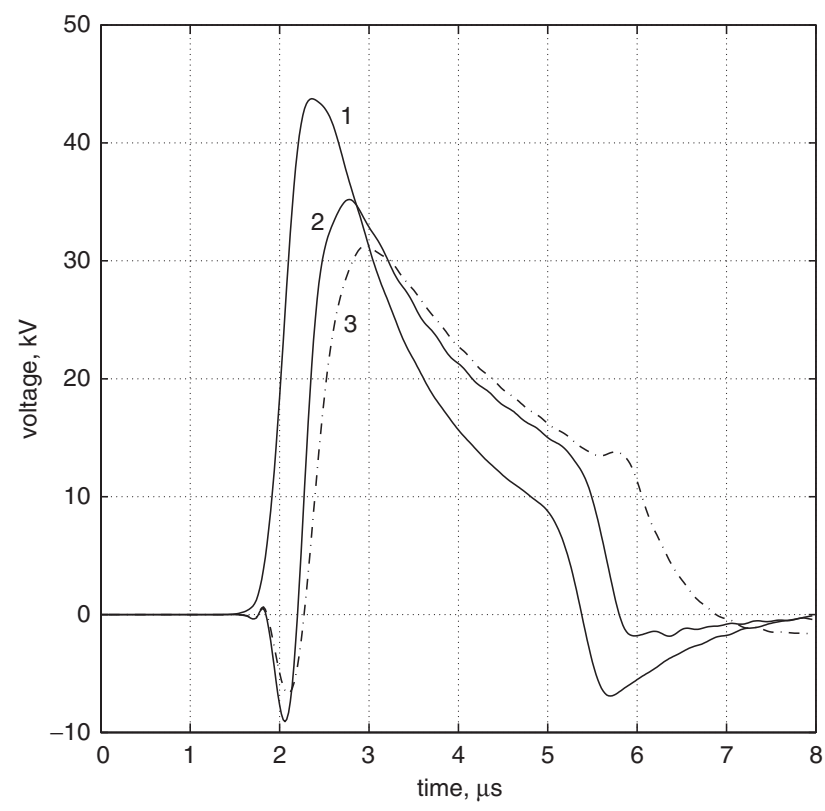

Fig. 7 Induced voltage on conductor 2 of single-circuit vertical configuration at line termination

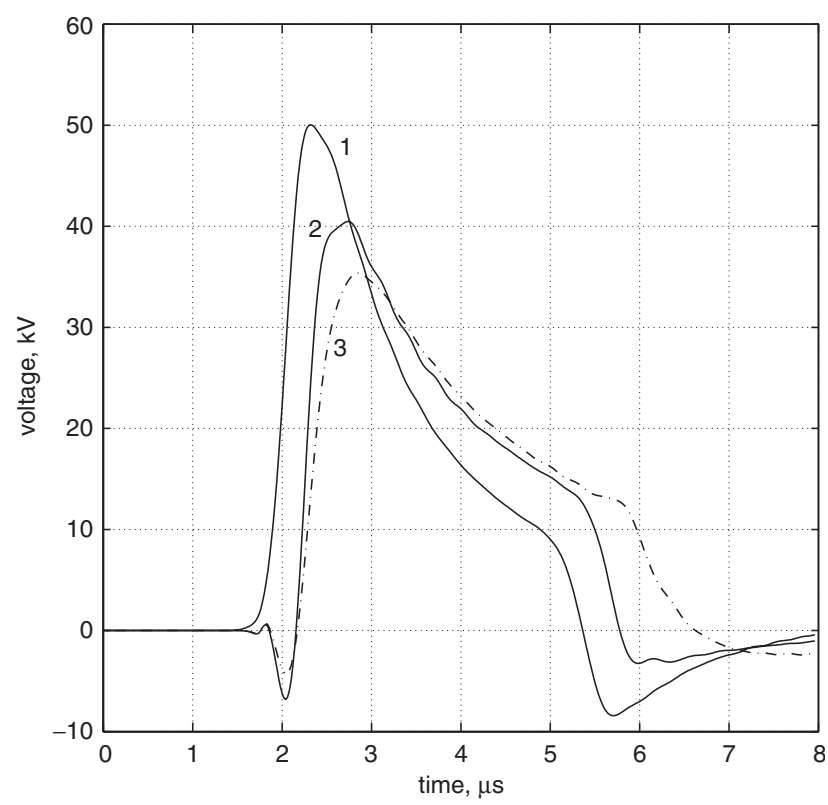

Fig. 8 Induced voltage on conductor 3 of single-circuit vertical configuration at line termination

Figures it can be seen that both the positive and negative peaks of the induced voltages get reduced when a finite conductivity is assumed for the ground. The reduction in peaks is much more when ground conductivity is included in the computation of both the horizontal electric field as well as in the coupling equation. There is also an initial negative prepulse in the induced voltage when a finite ground conductivity is included in the computation of the horizontal electric field. (Fig. 17).

At the mid-point of the overhead line, the positive peak of the induced voltage remains the same at about $80 \mathrm{kV}$ if ground is assumed as a perfect conductor, whereas it reaches about $145 \mathrm{kV}$ for a ground conductivity of $0.001 \mathrm{~S} / \mathrm{m}$ and relative permittivity of 10 for all three configurations studied. The negative peak reduces when a finite ground conductivity is assumed, as in the case of induced voltage at the line termination. It has been observed from the 


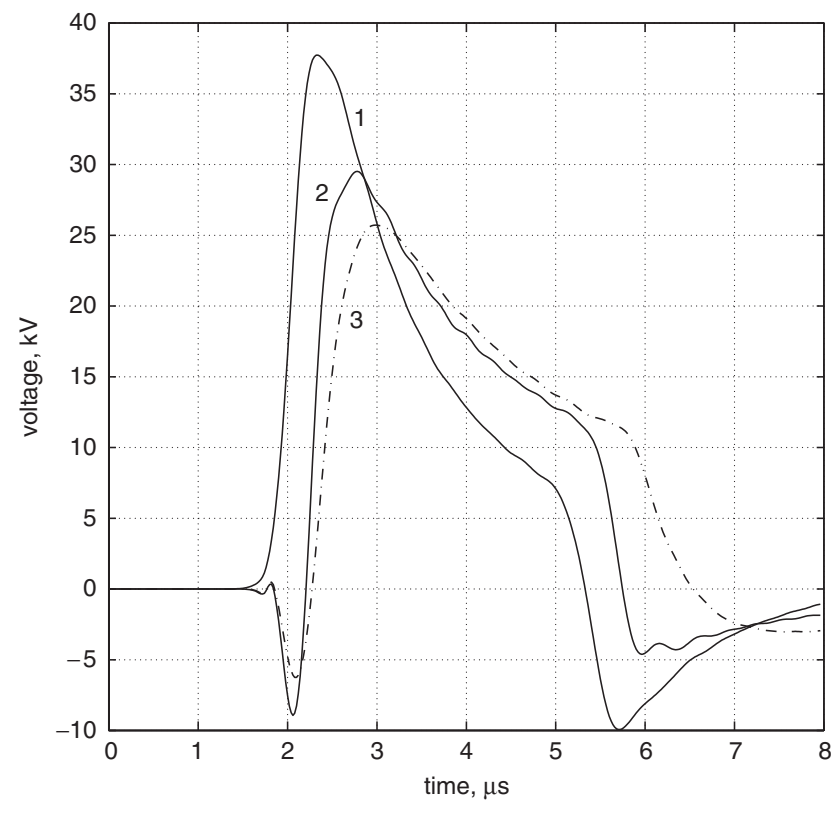

Fig. 9 Induced voltage on conductor 2 of single-circuit horizontal configuration at line termination

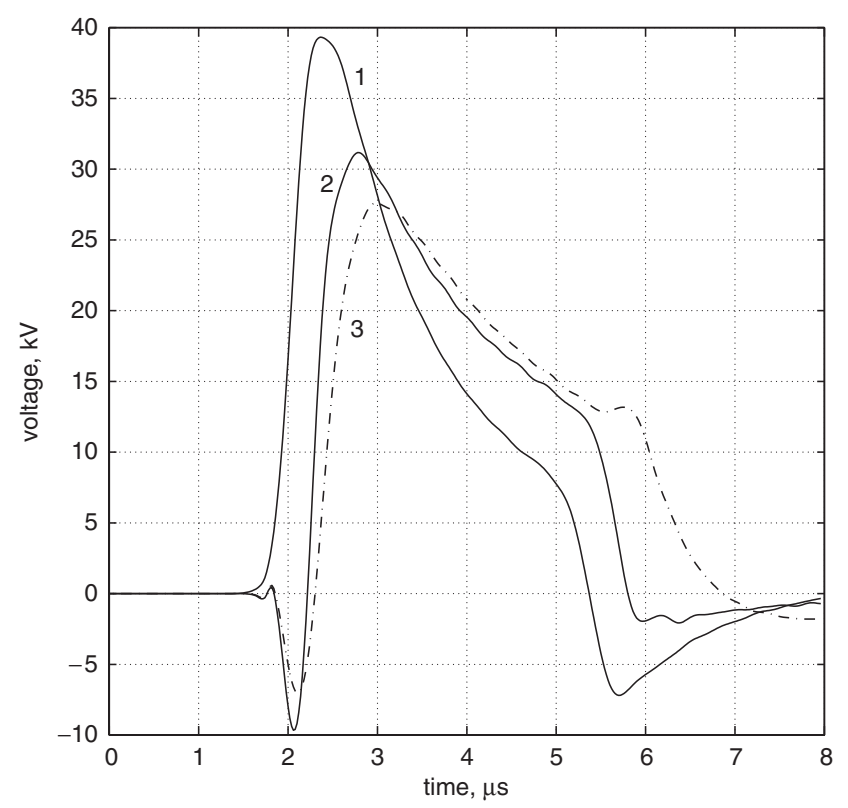

Fig. 10 Induced voltage on conductor 3 of single-circuit horizontal configuration at line termination

computation that the magnitude of negative peak voltage is more for double-circuit configuration as compared to the other two configurations. In this case, the initial prepulse is also not observed.

In general, it can be stated that finite ground conductivity decreases the magnitude of the induced voltage at the line termination, whereas it increases the induced voltage at the mid-point of the line for the location of the lightning stroke assumed. A similar observation was made for a single conductor above a finitely conducting ground [23].

The induced voltage at each point of the line is the result of the contribution of all the line segments that are illuminated by the lightning field. In the Agrawal coupling model, the magnitude and waveshape of the induced voltage on the overhead conductors depend mainly on the horizontal component of the electric field along the

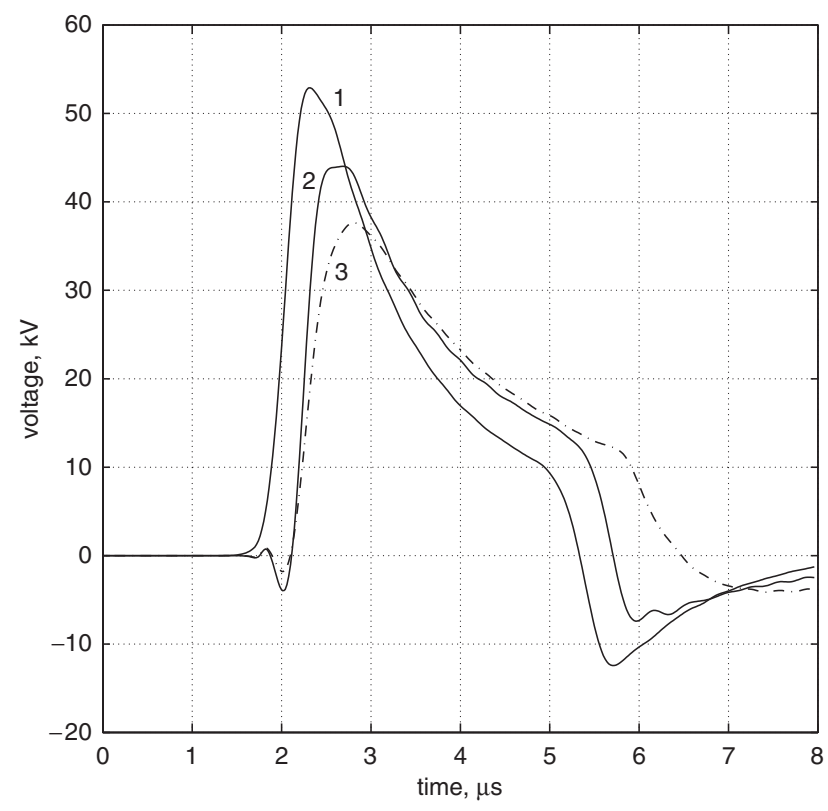

Fig. 11 Induced voltage on conductor 3 of double-circuit configuration at line termination

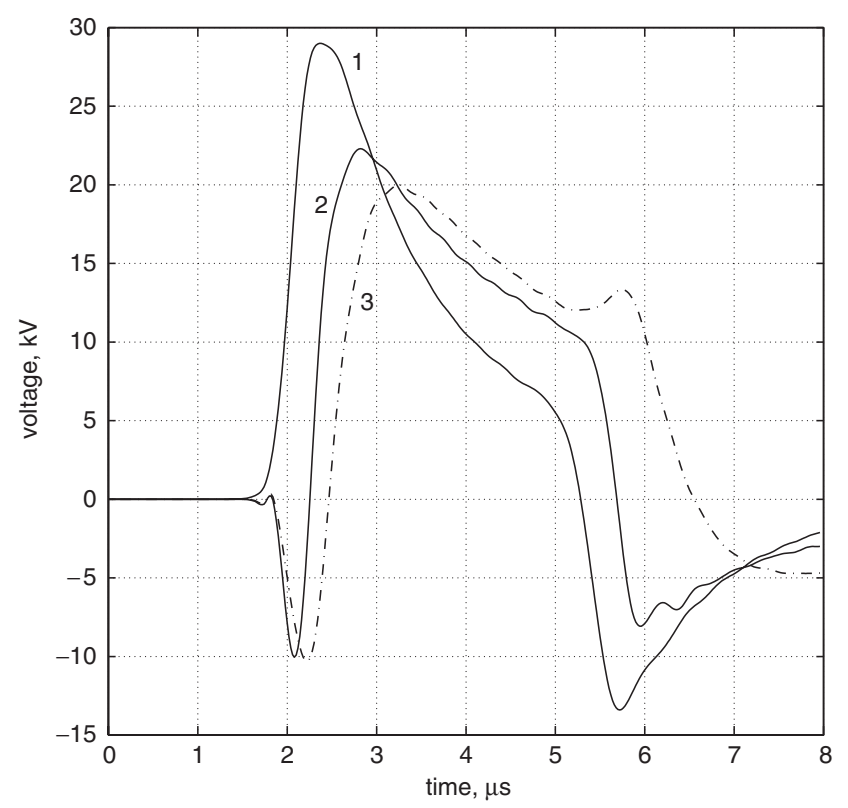

Fig. 12 Induced voltage on conductor 4 of double-circuit configuration at line termination

conductor for conductors a few metres above the ground and $1 \mathrm{~km}$ long. At line termination, the contribution of horizontal electric field is much higher than the contribution by the vertical electric field on the induced voltage for the lightning striking location chosen. For fast rising lightning currents and for low values of ground conductivity, the horizontal electric field exhibits an initial negative peak which produces, in turn, a negative initial peak in the induced voltage. However, at the mid-point of the line, the contribution of the vertical electric field on the induced voltage is overall positive in magnitude and it is higher than the voltage due to the horizontal electric field. Hence the induced voltage at line mid-point does not have an initial negative peak.

The plots show that on conductor 1 , which is at the same height and at the same distance from the strike point in all the three configurations studied, the induced voltage at the 


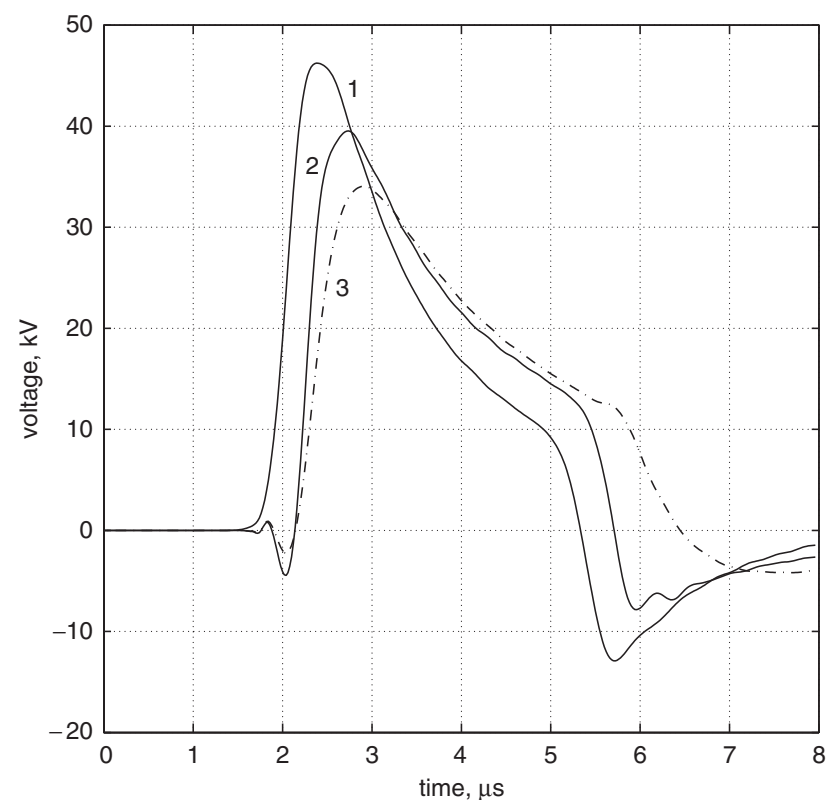

Fig. 13 Induced voltage on conductor 6 of double-circuit configuration at line termination

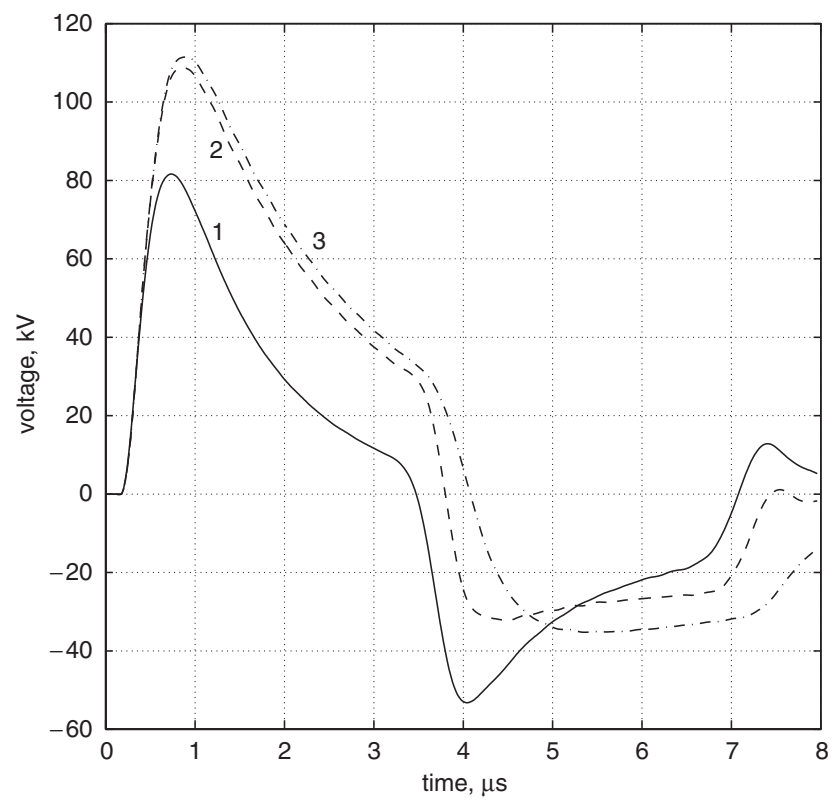

Fig. 14 Induced voltage on conductor 1 of vertical configuration at mid-point of overhead line

line termination is less for the double-circuit configuration case, in which the number of conductors are more. For the single-circuit vertical configuration, the positive peak of induced voltages on conductors 2 and 3 (see Figs. 7 and 8) are 44 and $50 \mathrm{kV}$, respectively, when ground is assumed as a perfect conductor. Since conductor 3 is at a higher level than conductor 2 , the induced voltage is also higher.

For the single-circuit horizontal configuration, the positive peak of the induced voltages on conductors 2 and 3 (Figs. 9 and 10) are 37 and $39 \mathrm{kV}$, respectively, when ground is assumed as a perfect conductor. Even though conductor 3 is at a farther distance from the lightning stroke location as compared to conductor 2 , the induced voltage on conductor 3 is higher than on conductor 2 . This is because the ground wire close to conductor 2 leads to a mutual coupling between the two, which in turn contributes to a reduction in the induced voltage on conductor 2 . The

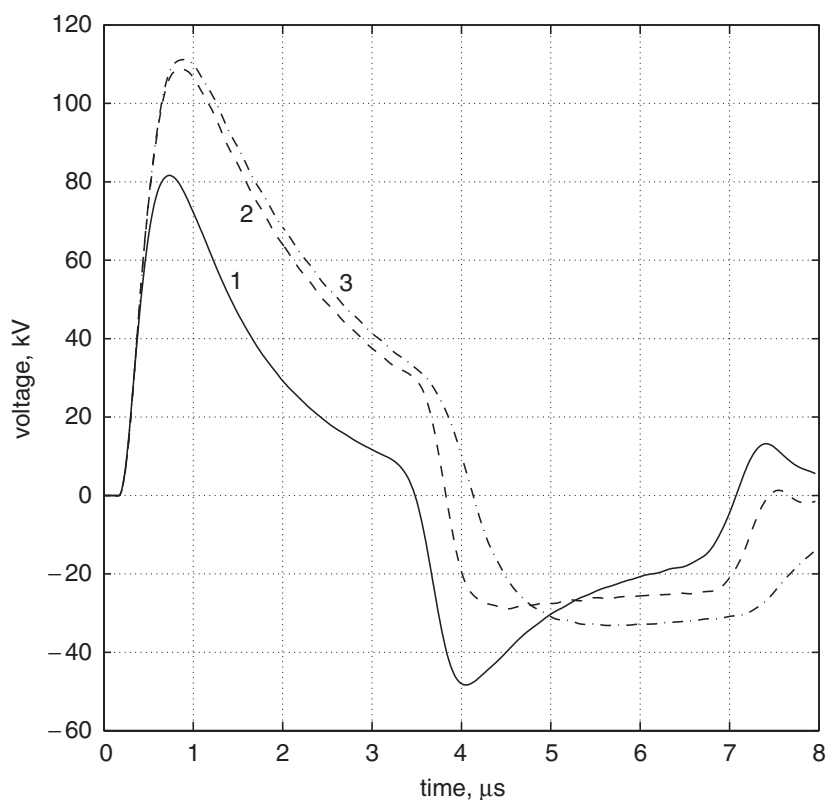

Fig. 15 Induced voltage on conductor 1 of horizontal configuration at mid-point of overhead line

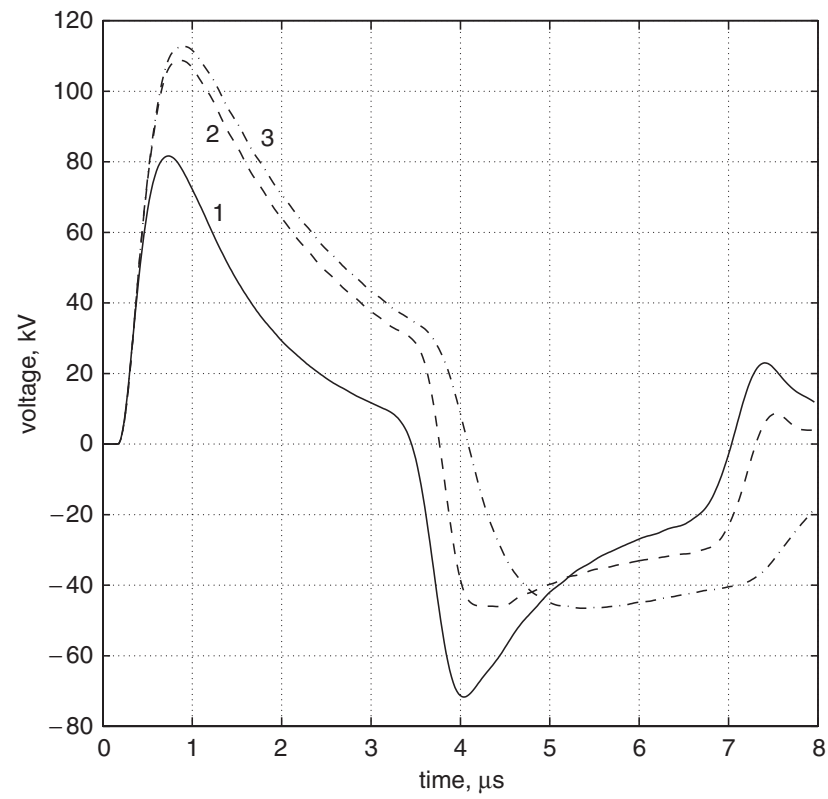

Fig. 16 Induced voltage on conductor 1 of double-circuit configuration at mid-point of overhead line

induced voltages on conductors 3,4 and 6 of the doublecircuit configuration (Figs. 11-13) show the expected trend. Conductor 3 is close to the lightning stroke location as compared to conductor 6 and hence the induced voltage is more on conductor 3 , even though both are at the same height.

The induced voltage at line termination is also computed for a single conductor of length $1 \mathrm{~km}$ at a height of $10 \mathrm{~m}$ above the ground. Figure 18 shows the induced voltage at line termination on conductor 1 , which is at the same height and same distance from the strike point for a single conductor, single-circuit vertical and double-circuit configurations. It is seen that the induced voltage at line termination is less for the double-circuit configuration case (which is about $20 \mathrm{kV}$ as against 27 and $40 \mathrm{kV}$ for the single-circuit vertical configuration and single conductor, respectively). This is because when the number of 


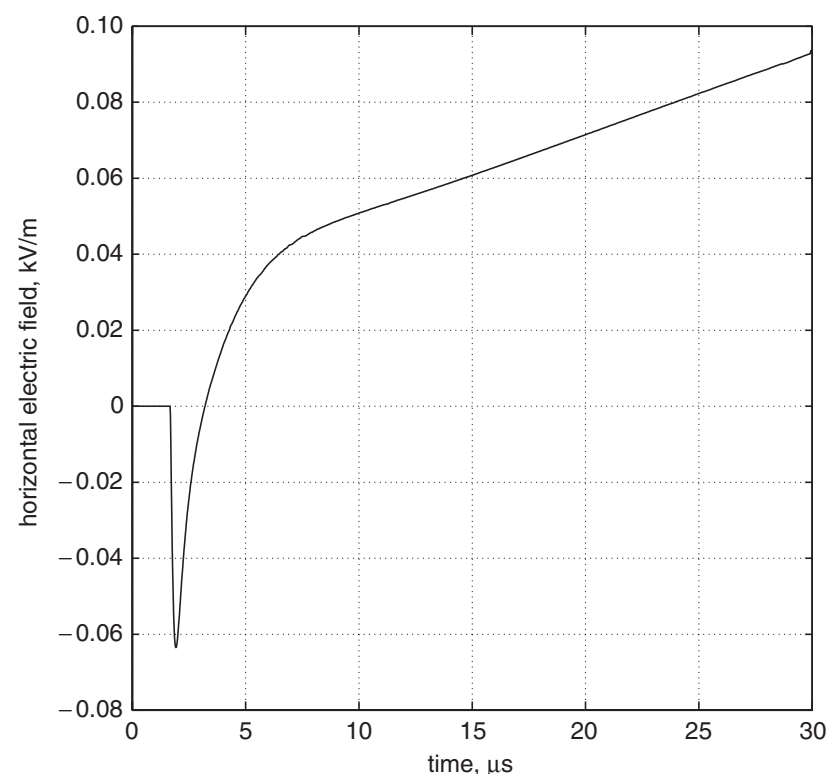

Fig. 17 Horizontal electric field at height $10 \mathrm{~m}$ and distance $500 \mathrm{~m}$ from lightning stroke for ground parameters $\sigma_{g}=0.001 \mathrm{~S} / \mathrm{m}$ and $\varepsilon_{r}=10$

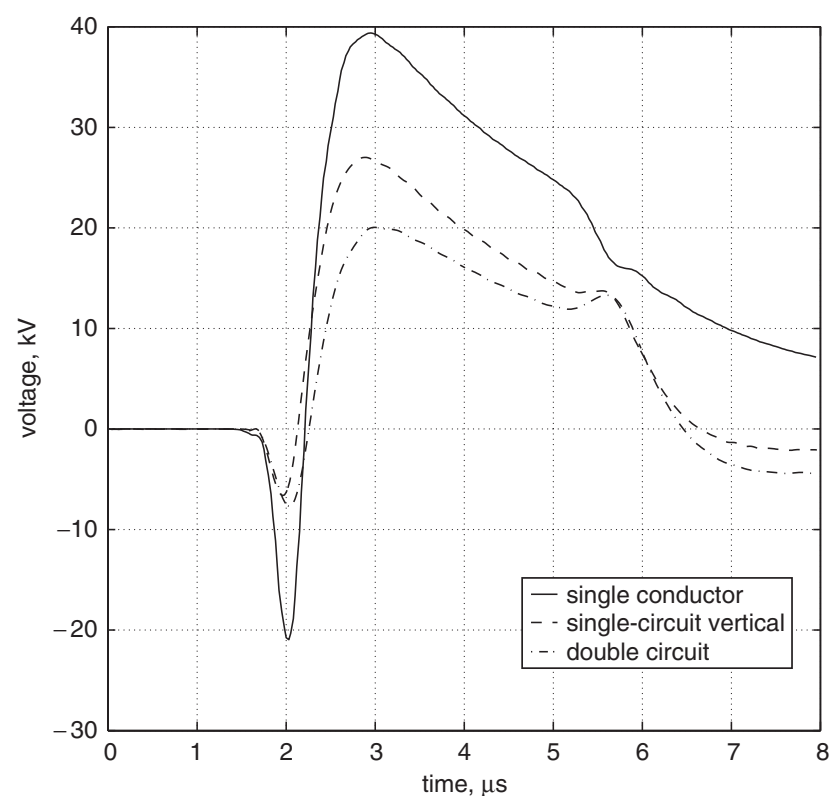

Fig. 18 Induced voltages at line termination on conductor 1, for single and multiconductor lines

conductors is higher, there is a mutual shielding coming into effect, thereby reducing the induced voltage. The waveshape of the induced voltage on a conductor in multiconductor system is also affected by the presence of the other conductors.

The lightning electric field induces current in all the conductors, including ground wire and phase conductors of the overhead line, which in turn produces magnetic field that couples with all the other conductors. This mutual coupling between the conductors decreases the induced voltage, which is very clearly seen at the line termination. However, at line mid-point, and for the lightning location chosen in this study, the influence of mutual coupling on the induced voltages gets nullified as the contributions from either side of the line mid-point cancel each other. Hence at line mid point, the induced voltage remains almost constant for the different configurations of the power distribution line studied.

\section{Conclusions}

Induced voltages on $33 \mathrm{kV}$, three-phase, single-circuit and double-circuit distribution lines due to indirect lightning stroke have been calculated. A low-frequency approximation has been used for the transient ground resistance term in the convolution integral appearing in the coupling equation, and the integral has been solved using a new expression. The first peak of induced voltage is found to be less at line termination when a finite ground conductivity is taken into account, whereas at the midpoint the induced voltage is more and remains constant for conductor 1 in all the three configurations studied. These results are relevant to the considered lightning stroke location. A finite ground conductivity also decreases the second peak of the induced voltage in both the cases. The presence of a higher number of conductors reduces the first peak of the induced voltage at line termination, whereas it remains almost constant at the midpoint of the line. The second peak increases with the number of conductors in both cases. The induced voltage at the line termination is less for the double-circuit line than for the single-circuit line.

\section{Acknowledgments}

The authors would like to record their sincere thanks and appreciation to the authorities of the Indian Institute of Science for permission to publish this paper. The first author thanks the Ministry of Human Resources Development, Government of India as well as National Institute of Technology Karnataka, Mangalore, for deputing him to take up the research programme on this topic. In addition, the support provided by CDC, Center for Continuing Education, IISc under the follow-up programme to write this paper is gratefully acknowledged.

\section{References}

1 Parrish, D.E.: 'Lightning-caused distribution transformer outages on a florida distribution system', IEEE Trans. Power Deliv., 1991, 6, (2), pp. 880-887

2 Eriksson, A.J., Stringfellow, M.F., and Meal, D.V.: 'Lightninginduced over voltages on overhead distribution lines', IEEE Trans. Power Appar. Syst., 1982, PAS-101, (4), pp. 960-969

3 Diendorfer, G.: 'Induced voltage on an overhead line due to nearby lightning', IEEE Trans. Electromagn. Compat., 1990, 32, (4), pp. 292-299

4 Moini, R., Kordi, B., and Abedi, M.: 'Evaluation of LEMP effects on complex wire structures located above a perfectly conducting ground using electric field integral equation in time domain', IEEE Trans. Electromagn. Compat., 1998, 40, (2), pp. 154-162

5 Rachidi, F., Nucci, C.A., Ianoz, M., and Mazzetti, C.: 'Response of multiconductor power lines to nearby lightning return stroke electromagnetic fields', IEEE Trans. Power Deliv., 1997, 12, (3), pp. $1404-1411$

6 Master, M.J., and Uman, M.A.: 'Lightning induced voltages on power lines: theory', IEEE Trans. Power Appar. Syst., 1984, PAS-103, (9), pp. 2502-2518

7 Nucci, C.A., Rachidi, F., Ianoz, M., and Mazzetti, C.: 'Lightning induced voltages on overhead lines', IEEE Trans. Electromagn. Compat., 1993, 35, (1), pp. 75-85

8 Guerrieri, S., Nucci, C.A., and Rachidi, F.: 'Influence of the ground resistivity on the polarity and intensity of lightning induced voltages'. 10th Int. Symp. on High Voltage Engineering, Canada, August 1997, pp. 199-202

9 Rachidi, F., Nucci, C.A., Ianoz, M., and Mazzetti, C.: 'Influence of lossy ground on lightning induced voltages on overhead lines', IEEE Trans. Electromagn. Compat., 1996, 38, (3), pp. 250-264

10 Rachidi, F., Nucci, C.A., and Ianoz, M.: 'Transient analysis of multiconductor lines above a lossy ground', IEEE Trans. Power Deliv., 1999, 14, (1), pp. 294-302

11 Nucci, C.A.: 'Lightning-induced voltages on overhead power linesPart I', Electra, 1995, (161) pp. 75-102

12 Uman, M.A.: 'Lightning return stroke electric and magnetic fields', J. Geophys. Res, 1985, 90, (D4), pp. 6121-6130

13 Rubinstein, M.: 'An approximate formula for the calculation of the horizontal electric field from lightning at close, intermediate and long ranges', IEEE Trans. Electromagn. Compat., 1996, 38, (3), pp. $531-535$ 
14 Agrawal, A.K., Price, H.J., and Gurbaxani, S.J.: 'Transient responce of multiconductor transmission lines excited by a nonuniform electromagnetic field', IEEE Trans. Electromagn. Compat., 1980, 22, (2), pp. 119-129

15 Tesche, F.M.: 'Comparison of the transmission line and scattering models for computing the HEMP response of overhead cables', IEEE Trans. Electromagn. Compat., 1992, 34, (2), pp. 93-98

16 Sunde, E.D.: 'Earth conduction effects in transmission systems' (Dover Publications, New York, USA, 1968)

17 Vance, E.F.: 'Coupling to shielded cables' (Wiley Interscience, New York, USA, 1978)

18 Orzan, D.: 'Time-domain low frequency approximation for offdiagonal terms of the ground impedance matrix', IEEE Trans. Electromagn. Compat., 1997, 39, (1), p. 64
19 Loyka, S.L.: 'On calculation of the ground transient resistance of overhead lines', IEEE Trans. Electromagn. Compat., 1999, 41, (3), pp. 193-195

20 Rachidi, F., Loyka, S.L., Nucci, C.A., and Ianoz, M.: 'A new expression for the ground transient resistance matrix elements of multiconductor overhead transmission lines', Electr. Power Syst. Res., 2003, 65, pp. 41-46

21 Brigham, E.O.: 'The fast fourier transform' (Prentice-Hall Inc., New Jersey, USA, 1974)

22 Costa, F.S., and Miranda, G.C.: 'Comparison of lightning tower surge models using the EMTP'. 10th Int. Symp. on High Voltage Engineering, Canada, August 1997, pp. 327-330

23 Nucci, C.A.: 'Lightning-induced effects on transmission lines'. Proc. 14th Int. Zurich Symp. on Electromagnetic Compatibility, Zurich, February 2001, Invited tutorial 